\title{
Posibilidades del cooperativismo en un nuevo modelo de servicios públicos sociosanitarios y su concreción en el País Vasco
}

\section{Santiago Merino}

\section{RESUMEN}

El artículo pretende reflexionar sobre las posibilidades de la fórmula cooperativa en relación a la prestación de los servicios públicos sociosanitarios en el País Vasco. Así, se comienza con un repaso al concepto jurídico de servicio público, atendiendo a las líneas de reforma que se están produciendo en el mismo, para pasar a continuación a las nuevas tendencias doctrinales sobre la gestión pública, la cual debe caracterizarse, a nuestro entender, por la eficacia y la participación de los administrados. Se abordan los diferentes instrumentos de gestión pública, y por ende de contratación pública, para atender a continuación a la necesaria justificación de la fórmula cooperativa como la herramienta más adecuada para la gestión de lo público en el ámbito sociosanitario, algo que, si bien parte de un aspecto general, se concreta en el ámbito territorial vasco (Comunidad Autónoma del País Vasco). En este marco territorial se analizan las políticas de promoción de las sociedades cooperativas, así como la singular normativa que regula las Cooperativas de Utilidad Pública y las de Iniciativa Social, sin olvidar las experiencias habidas en nuestro entorno más cercano. El artículo finaliza con la obligada fase conclusiva que nos proyectará al futuro con la esperanza del liderazgo de esta fórmula participativa.

PALABRAS CLAVE: Servicios públicos, gestión pública, servicios sociosanitarios, economía social, cooperativismo, cooperativas sanitarias.

CLAVES ECONLIT: J54, J58, L30, L33, P13.

Cómo citar este artículo / How to cite this article: MERINO, S. (2016): "Posibilidades del coopera-

tivismo en un nuevo modelo de servicios públicos socio sanitarios y su concreción en el País Vasco", CIRIEC-España, Revista de Economía Pública, Social y Cooperativa, 87, 139-176.

Correspondencia: Santiago Merino, Letrado del Consejo Superior de Cooperativas de Euskadi, Reyes de Navarra 51, 01013 Vitoria-Gasteiz; e-mail: santi@csce-ekgk.coop. 


\section{EXPANDED ABSTRACT}

\section{Possibilities of cooperativism in a new public social and health services model and its implementation in the Basque Country}

The aim of the article is to reflect on the possibilities offered by the cooperative approach in relation to the provision of public social and health services in the Basque Country, a reflection that has become necessary within a context of growing questions about the provision of certain services by the public authorities, as a result of the economic crisis. Therefore, we have examined the different ways and methods that can be used to approach the provision of social and health services in the public sector, and thus help to maintain the Welfare State that has been characteristic of our western society in recent decades.

For that purpose, the design was based on a scientific protocol with a legal basis, supported by the data that we were able to obtain with the assistance of the Higher Council of Cooperatives of the Basque Country and the Basque Government's Basque Health Service - OSAKIDETZA.

The methodology used was to conduct comparative studies (using two countries - one from the English-speaking world and another from the Latin world), and comparing the practical realities in the aforementioned social and health sector. There is also a detailed analysis of the applicable legislation, both in the Basque Country and the Spanish state.

We have defined the legal concept of public service, taking into account the areas of reform that are currently underway, before examining the latest trends in approaches to public administration, which, in the author's opinion, should be characterised by efficiency and the participation of citizens. Furthermore, we examine the different instruments of public administration and, therefore, of public procurement, before proceeding to discuss the need to justify the cooperative approach as the most suitable tool for the management of public social and health services, starting with an overview before specifically examining it within the scope of the Basque territory (Autonomous Community of the Basque Country).

From the results obtained, we can highlight the following:

- There is currently a trend to reform the public sector in order to improve economic management capacity and efficiency in the provision of its services.

- New Public Management indicates that Public Administration should emulate the best practices of the institutions from the private sector and that, although Public Administration cannot be managed like a company, it can be run with an entrepreneurial spirit. 
- It is within this context that the provision of public services by private operators has emerged, more specifically by Social Economy Organisations, because the participation of the citizen/customer in the management of services has been shown to yield good results, for example, in the case of experiences in the field of social health and in social services.

- The Social Economy reveals a business model that is not characterised by size or the area of activity, but by respect for shared values, such as the primacy of democracy, participation of social stakeholders and the individual, and social objectives over personal gain; the defence and implementation of the principles of solidarity and responsibility; the combined interests of its user members with the general interest; democratic control exercised by the members; voluntary and open membership; management autonomy and independence in relation to public authorities; and the allocation of the bulk of surpluses in pursuit of goals such as sustainable development, and service to its members according to the general interest.

- Within the realm of Social Economy, cooperatives are a form of business organisation, based on democratic structure and functioning. They perform their activities while adhering to cooperative principles: the voluntary and open membership of members (door always open), democratic management (one person = one vote), the economic participation of its members (share in the profits, based on the member's work and not their capital), education, training and information (economic democracy school) and interest in the community (sustainable development and local democratic engagement).

- In the Basque Country, the cooperative model, which must be specifically promoted by constitutional mandate, offers safeguards for the public sector, such as the existence of a specific administrative register or a conflict resolution service, also in a public venue, which currently make this approach especially attractive for performing any activity or providing services (including public services).

- There is legislation specific to the Basque Country (Basque Government Decree 64/1999, of 2 February, governing public interest cooperative societies; and Decree 61/2000, of 4 April, governing Social Initiative Cooperatives) which ensures that the cooperative approach is even more suitable for the management of social and health services, even allowing public authorities to be part of the Cooperatives that manage those services to ensure proper control and oversight.

- Regarding the Promotion of Personal Autonomy and Care of Dependent Adults, and the Social Services in general, there has been strengthening of public accountability, full use of the available resources and cooperation between the different actors through the coordination of public and private actions as a whole. This public/private cooperation means that we see Cooperatives and, more specifically, social initiative and/or public interest cooperatives, as one of the most suitable tools for the management of this type of service.

Regarding the limitations of the research, we can say that there is little specialised literature about the subject of the study, and that there are practical realities that are still emerging, at least within the territory that is the subject of the study. However, all sources consulted have shown us that there are 
major implications, to the extent that they all agree that there is a problem with the management of social and health services, and that this will surely become worse over the coming years.

Moreover, with regard to its original value, it is necessary to note that we have found no other study with the same characteristics, as it is undoubtedly highly topical, given the need for care for dependent adults in the current economic climate.

Finally, the article presents unquestionable practical conclusions, insofar as it makes proposals that can be used by the Public Administration, in the form of the different cooperative approaches to the management of social and health services. Although these proposals focus on the Basque Country, they could also be applied in other Autonomous Communities, if suitably adapted.

KEYWORDS: Public services, public administration, health and social services, social economy, cooperativism, health cooperatives. 


\section{1.- Las líneas de reforma en la prestación de servicios públicos (ámbito sociosanitario): hacia la nueva gestión pública 1}

En la actualidad se puede apreciar cómo en el sector público se busca aumentar la eficacia en la prestación de servicios adaptándose a las condiciones comarcales concretas a la hora de abordar las necesidades de la comunidad; al tiempo que se han realizado algunos esfuerzos tendentes a la generación de conciencia en relación con los costos y la eficacia de la producción de servicios estrechando los vínculos entre la asignación y la utilización de los mismos.

Por otro lado, y en el capítulo de las líneas de mejora continua, apreciamos que la tendencia debe ser sin duda la participación de los usuarios del servicio en actividades de seguimiento y evaluación mismo, creando sistemas y procedimientos de participación en la planificación, asignación, supervisión y evaluación, sino en la cogestión planificada integral del servicio, garantizando con ello la prestación del servicio público, pero enmarcado en la responsabilidad pública, la transparencia y la legitimidad, así como en la eficiencia del servicio.

No cabe duda que nos encontramos con grandes retos en el sector público, en el marco de la actual crisis económica, que ha hecho incluso que se estén cuestionado no sólo la forma de prestación de los servicios públicos, sino incluso si determinados servicios deben prestarse desde el propio ámbito público.

Para adecuarse a los nuevos tiempos, se requiere por parte de la Administración, de alguna forma, un cambio de mentalidad, de funcionamiento y de estructuras, sumándose a la revolución que experimenta actualmente el ámbito de la gestión de las organizaciones.

En el actual marco económico ${ }^{2}$, y en definitiva de la nueva gestión pública, hemos de remitirnos a las nuevas tendencias provenientes del management privado, ya que precisamente el conjunto de técnicas, valores y principios que inspiran éste se ha convertido también en una de las principales fuentes de inspiración de la modernización del sector público en los países occidentales. Este enfoque, defendido por la New Public Management (Nueva Gestión Pública), pone su énfasis en la eficiencia y la eficacia del sector público.

1.- Nota: La investigación que se publica en toda su extensión ha dado lugar a diversas comunicaciones que si bien abarcan cuestiones distintas han traído causa de ésta, en concreto las comunicaciones presentadas y admitidas en el Congreso de Ciriec-España de investigadores en economía social y cooperativa celebrado en Santander el 25 de septiembre de 2014, y en el $30^{\circ}$ Congreso de Ciriec Internacional, celebrado en Buenos Aires (Argentina) entre los días 29 y 31 de octubre de 2014.

2.- A. Giddens ha avisado del desarrollo de la economía hacia un "sistema post-escasez» cuyos criterios centrales de éxito son menos el crecimiento y más bien la justicia y sostenibilidad. Aplicados estos criterios a las organizaciones, y más en concreto al sector público, para su evaluación institucional, entonces la eficiencia ya «no significa la optimización del rendimiento de los recursos empleados, sino la capacidad para considerar necesidades, recursos y valores diferenciados. Vid. Giddens, A., Konsequenzen der Moderne, Frankfurt, 1997. 
Lo que no cabe duda es que vivimos tiempos en los que el mundo -también la Administración Pública- está, literalmente, reinventándose a sí mismo. A lo largo de los últimos años, la mayoría de los países del mundo occidental están poniendo en marcha ambiciosas propuestas para transformar en profundidad sus sistemas administrativos públicos, motivados en muchas ocasiones por profundas reflexiones y en otras por una obligada realidad presupuestaria.

En esta tendencia de reflexión, se suele decir que los criterios empresariales están invadiendo el campo de lo público. Incluso, desde posiciones neoliberales se ha llegado a cuestionar la capacidad intrínseca del Estado para administrar los servicios, defendiendo la vasta corriente privatizadora y el desarrollo de la ideología de la «Public Choice» (Savas, Tullock y Niskanen). Estos postulados señalan, en esencia, que cada individuo procura maximizar su propio bienestar, y el mercado constituiría el instrumento más eficiente para el logro de este objetivo.

Frente a esto, la mayoría de las reformas que se empiezan a implementar en nuestro entorno más cercano, pueden ser consideradas como expresión de la ya citada New Public Management que señala que la Administración Pública debiera emular las mejores prácticas de las instituciones del sector privado y que si bien no se puede manejar la Administración Pública como una empresa, sí se puede dirigir con espíritu emprendedor.

Se parte como premisa en esta nueva gestión del reconocimiento de la propia Administración Pública como el marco adecuado para adoptar decisiones que afectan a la comunidad, como bien señalan Osborne y Gaebler ${ }^{3}$. Sin embargo, la sociedad actual no puede funcionar eficazmente sin un gobierno eficaz y parece evidente que el problema no reside en las personas que trabajan en el actual sector público, sino en los sistemas en los cuales trabajan. Por ello, pensamos que la crisis de lo público está focalizada en que un modelo de gobierno centralizado y jerárquico, que no encontramos en las sociedades dinámicas, orientadas a la información y a los cambios vertiginosos en los que nos encontramos. Todo ello nos lleva, sin lugar a dudas, a un cambio de parámetros en el ámbito público y en la prestación de los servicios que se garantizan y ofertan desde el mismo.

Así, se propone un nuevo estilo de gestión de lo público basado en la legitimidad de la propia Administración Pública, la promoción de la participación de la sociedad civil en los asuntos públicos, la competitividad en la prestación de los servicios, la transformación de las organizaciones, la correcta financiación atendiendo al resultado, la satisfacción del cliente (y no de la tecnocracia creada), la previsión, la descentralización, la orientación al mercado y la filosofía empresarial como visión en la medida que la Administración Pública es una empresa de servicios que ha de emplear eficiente y eficazmente el dinero de sus clientes, los ciudadanos.

Como ya hemos señalado, la New Public Management pone énfasis precisamente en la eficiencia y la eficacia de la Administración Pública. No basta con la «legitimidad de origen», otorgada por el

3.- Osborne, D. y Gaebler, T.: La reinvención del gobierno, Barcelona 1994. 
voto popular, sino que la ciudadanía tiende cada vez más a evaluar la gestión pública por los resultados. La «reinvención» implica orientar el sector público hacia el usuario que es considerado «cliente»; pasar de una «administración de potestades» a una «moderna empresa de servicios».

En este marco, el futuro viene marcado por una clara separación entre la «política» (Policy Making) y la Administración y gestión de los servicios públicos (Service Delivery). La planificación y la toma de decisiones se debe realizar a través de objetivos (Management by Objectives), presupuestos orientados a productos (Management by Results y Products), y competencias (Management by Delegation), siendo la calidad la expresión de una nueva filosofía de gestión 4 .

En este marco se ha generalizado la idea de licitar los servicios administrativos (Competitive Tendering) y transferir a terceros actividades propias de la Administración Pública (Contracting Out), algo que puede constituir una excelente herramienta para abaratar costos y mejorar los servicios, además de para optimizarlos desde la gestión eficiente. Lo esencial de la acción pública «no reside en prestar servicios, sino en asegurar que éstos se presten». Detrás de esto está el concepto de «Enabling Authority», o la idea de Administración Pública como ente «facilitador» 0 «habilitador».

Esta vocación no tanto de ofertar directamente servicios sino garantizarlos, facilitarlos, busca la eficiencia en la asignación a través de una mejor adaptación de los servicios públicos a la realidad social, y en el caso que nos ocupa el de los sociosanitarios; y la eficiencia productiva a través de una mayor rendición de cuentas de la propia Administración Pública a los ciudadanos. Y, sin embargo, ninguno de los dos se concreta de forma generalizada en el sector público actual.

Para atender a estos factores desde el ámbito público, se torna prioritario la detección de las necesidades y, por consiguiente, una mejor definición de las respuestas posibles. Entre las medidas planteadas se encuentran la utilización de técnicas de investigación social aplicada para mejorar la detección y formulación de las necesidades y demandas sociales; la definición de los público-objetivos o segmentos a los que se va a prestar el servicio público, el diseño de estrategias de comunicación y; el establecimiento de canales de participación de los ciudadanos-clientes entre otros. Así, el diseño de las características operativas del servicio implica, por un lado, que éste se adapte de la mejor forma posible a la demanda de la ciudadanía y, por otro, a las características del entorno en el que se va a desarrollar la prestación. Por eso, es preciso la generación de nuevas capacidades de organización, una nueva relación sector público y cliente/administrado, democratización y modernización de la gestión gubernamental, acercamiento de las mismas a las necesidades de la población, legitimación de las políticas públicas e institucionalización de la participación ciudadana, racionalización de los procedimientos de gestión, ahorro de costes de gestión y optimización con ello de los recursos públicos 5 .

4.- En este sentido de anticipación a los cambios, vid. Friedmann, Reinhard, La Gestión Pública en el siglo XXI. Anticipando los cambios que vienen. Hacia un Sector Público Inteligente y en constante Aprendizaje. Instituto de estudios y Gestión Pública, Madrid, 2003.

5.- En este sentido se manifiestan Ábalos Meco, José Luis e Illán Sailer, Juan Carlos, op. cit. 
No podemos obviar que los nuevos diseños que tratamos encuentran las previsibles resistencias al cambio. Así, nos encontramos con procesos profundamente políticos que a menudo cuentan con la oposición de grupos que tienen intereses creados para mantener su histórico status quo y que en principio puede que pierdan influencias si el pretendido cambio llegara.

El clientelismo y la politización del sistema suelen ser factores que impiden la prestación eficaz de los servicios, si bien se constata que su asentamiento en el sistema aparece como una evidente oposición a priori a cualquier tipo de cambio. También puede darse una resistencia sindical ante las reformas que intentan mejorar el desempeño mediante, por ejemplo, propuestas de mejor control interno y mayor flexibilidad administrativa.

Por estas razones resulta fundamental implicar a los empleados públicos y a los sindicatos en esta labor a través de incentivos salariales y de promoción profesional, la introducción de "controles sociales", o la elaboración de un plan de capacitación permanente para los empleados públicos. Esto, que supondría una modificación del marco legal para la función pública, encuentra su vehículo a la hora de garantizar su aplicación en la gestión delegada o compartida con empresas autogestionarias de la economía social.

En este contexto surge a nuestro entender la potencialidad del sector privado autogestionario y participativo, consolidando la idea de la superación de fronteras en cuanto a la prestación de los servicios públicos, espacios económicos en los que sus miembros redefinen permanentemente sus tareas de acuerdo a las necesidades y en donde las decisiones no son tomadas, en principio, por un superior de una instancia central, sino que se derivan de interacciones emergentes, descentralizadas y auto-organizadas. Estos espacios, significan la reinvención permanente de la organización, como una banda de jazz, en la que se reúnen intérpretes que tocan la pieza musical desde su individualidad. La integración de sus realizaciones creativas es lo que más importa. Los integrantes de la banda tienen que estar en condiciones de escuchar a los otros, y de establecer un diálogo con ellos. Han de ser capaces de resonar, es decir: entrar en onda, hacer suyos los temas, variarlos, exponerse y retirarse en el momento preciso. Este modelo es como debería funcionar una organización moderna, también pública 0 aquella que presta servicios públicos, como una entidad flexible y con capacidad de innovación; como una organización en que se trabaja sin partitura, sin libreto y sin dirigente (liderazgo compartido). Igual que en una banda de Jazz, la organización tiene que convertirse en un campo creativo y sinérgico 6 .

Al Estado le corresponde, no el deber de formular objetivos obligatorios e implementarlos a través de un enorme aparato burocrático, sino que le compete fundamentalmente garantizar condicionesmarco apropiadas en las que se implementen nuevos métodos de participación, y en donde es fácil

6.- Ver los excelentes trabajos: Barrett, F.: Creativity and Improvisation in Jazz and Organizations: Implications for Organizational Learning, en: Organization Science, 9, 5, septiembre-octubre de 1998; Hatch, M.J.: Jazzing, Up The Theory of Organizational Improvisation, en: Advances in Strategic Management, Volume 14, 1997; y en nuestro entorno más cercado Ugarte, Luxio, Sinfonía o Jazz, Koldo Saratxaga y el modelo Irizar, Barcelona, 2004. 
encontrarse con el fenómeno cooperativo. Se propone, por tanto, el desarrollo de una "democracia cooperativa", es decir modelos políticos deliberativos, de participación ciudadana, que incluyan métodos de formar opinión que promueven la democratización de la forma clásica de gobierno.

Y esta cooperación no debe manifestarse tan sólo en las fases decisionales, sino también en las de ejecución y en las de evaluación; donde las diferentes fórmulas de la Economía Social, y muy particularmente la cooperativa, nos aparecen como fenómeno empresarial para ser implementado a la hora de la prestación de los servicios públicos.

\section{2.- El contrato administrativo de servicios como instrumento de gestión indirecta y las clausulas sociales}

Llegados a este punto, debemos detenernos en la contratación externa como una fórmula de entrega a manos privadas de la producción de servicios o actividades prestacionales de carácter público, al tiempo que se mantiene la financiación pública7 ${ }^{7}$.

Las características de la contratación externa, y más en concreto la referente a los servicios sociosanitarios, la hacen plenamente adecuada para resolver las necesidades de algunos servicios. Para el oportuno seguimiento de este tipo de contratos diremos que no podrán ser objeto de éstos aquellos servicios que impliquen ejercicio de autoridad inherente a los servicios públicos (es el ejemplo de la inspección sanitaria), y que las empresas adjudicatarias deberán ser personas físicas o jurídicas cuya finalidad o actividad tenga relación directa con el objeto del contrato.

$Y$ en este marco de entrega a manos privadas de determinados servicios públicos (en especial los sociosanitarios), diremos que existen pruebas que demuestran el impacto positivo que tienen las reformas orientadas a aumentar la participación de las organizaciones privadas, preferentemente sin ánimo de lucro, en la prestación de servicios públicos, cuando las condiciones son adecuadas de cara a la mejora tanto de la eficiencia como de la calidad de la prestación de estos servicios. Sin duda, estamos haciendo referencia a las Entidades de la Economía Social, y más en concreto a las sociedades cooperativas.

7.- El artículo 10 del Texto Refundido de la Ley de Contratos del Sector Público establece que son contratos de servicios aquellos cuyo objeto son prestaciones de hacer consistentes en el desarrollo de una actividad o dirigidas a la obtención de un resultado distinto de una obra o un suministro. 
Dicho esto, debemos detenernos en la fórmula jurídica, siempre en el marco del contrato de servicios, que posibilitaría tales adjudicaciones, y no es otra más que a través de la incorporación de cláusulas concretas de discriminación positiva en los concursos públicos.

Entendiendo por cláusula cada una de las disposiciones que estipulan el contenido de un contrato, estableciendo derechos y deberes de obligado cumplimiento para las partes, deberemos atender a la posibilidad que en los concursos públicos aparezcan lo que se ha venido a llamar "Cláusulas Sociales", en la medida que incluyan aspectos de política social en los procesos de contratación pública8.

Estas cláusulas podrán establecerse en las diferentes fases de contrato público, esto es: en la admisión, exigiendo requisitos previos de carácter social o, en su caso, ausencia de ánimo de lucro o por ejemplo la acreditación de experiencia o solvencia técnica en materia de inserción sociolaboral para que la empresa pueda ser contratada; como criterio de valoración, señalando características 0 compromisos de carácter social que serán baremados o puntuados en la adjudicación del contrato; o por último, en la fase de ejecución, señalando por ejemplo que un porcentaje de la plantilla que ejecutará el contrato sean personas con dificultades de acceso al empleo.

En el caso que no ocupa no podemos más que reafirmarnos y reivindicar la incorporación de estas cláusulas entre otras razones porque la actuación de las Administraciones Públicas, y por lo tanto la contratación pública, debe pivotar en torno al interés público. No se trata de una mera posibilidad sino de una exigencia establecida en el punto 1 del artículo 40 de la Constitución de 1978 cuando señala que "Los poderes públicos promoverán las condiciones favorables para el progreso social y económico y para una distribución de la renta regional y personal más equitativa, en el marco de una política de estabilidad económica. De manera especial realizarán una políica orientada al pleno empleo".

Entendemos por tanto que la contratación administrativa se encuentra sujeta al interés público y el mismo, en muchas ocasiones, sólo se ha considerado en relación con el objeto directo del contrato; es decir, con la obra, la prestación del servicio o el suministro que constituyen las concretas obligaciones que el contratista se compromete a realizar. El valor interpretativo de los principios rectores tiene aquí el sentido de introducir en la figura del contrato administrativo otros intereses públicos que trascienden el objeto directo de cada contrato individualmente considerado. Se trata de concebir la contratación administrativa, gracias a la inclusión de cláusulas sociales, como un instrumento para llevar a cabo políticas públicas transversales. Los principios rectores obligan a integrar la contratación administrativa con el conjunto de políticas que persiguen los poderes públicos ${ }^{9}$.

8.- Sobre las cláusulas sociales, vid, por todos, Legesma Zabalegui, Santiago, Cláusulas sociales, contratación pública e inserción social, Bilbao, 2006.

9.- En este sentido la Sentencia del Tribunal Supremo de 23 de mayo de 1997, cuando establece claramente que la Administración no está obligada a aceptar el mejor precio, sino la oferta más favorable al interés público". 
Esta posibilidad de establecer una reserva del mercado público a través de la contratación, ya se hallaba expresamente recogida en la Directiva 2004/18/CE del Parlamento Europeo y del Consejo de 31 de marzo de 2004, sobre coordinación de los procedimientos de adjudicación de los contratos públicos de obras, de suministro y de servicios. A este respecto ya indicaba, por ejemplo, en su considerando número 28 que "el empleo y la ocupación son elementos clave para garantizar la igualdad de oportunidades en beneficio de todos y contribuyen a la inserción en la sociedad. En este contexto, los programas de talleres y empleos protegidos contribuyen eficazmente a la inserción o reinserción de personas con discapacidad en el mercado laboral. Sin embargo, en condiciones normales de competencia, estos talleres pueden tener dificultades para obtener contratos. Conviene, por tanto, disponer que los Estados miembros puedan reservar a este tipo de talleres el derecho a participar en los procedimientos de adjudicación de contratos públicos o reservar su ejecución en el marco de programas de empleo protegido". Esta Directiva resultaba de obligado cumplimiento para los Estados y a ella se adaptaron -en similares términos- primero la Ley 30/2007, de 30 de octubre, de Contratos del Sector Público (Vigente hasta el 16 de diciembre de 2011), y más recientemente en la actualidad el Real Decreto Legislativo 3/2011, de 14 de noviembre, por el que se aprueba el texto refundido de la Ley de Contratos del Sector Público ${ }^{10}$.

En relación a la contratación de servicios, no podemos olvidar las importantísimas modificaciones que han introducido la Directiva 2014/24/UE, de 26 de febrero de 2014, sobre contratación pública y por la que se deroga la ya citada Directiva 2004/18/CE; y la Directiva 2014/23/UE, de 26 de febrero de 2014 , relativa a la adjudicación de contratos de concesión. De acuerdo con lo dispuesto en el artículo 51 de esta última, 90 de la primera y 106 de la Directiva de Sectores especiales, el plazo de transposición de las mismas concluyó el 18 de abril de 2016 para la mayor parte de su contenido ${ }^{11}$.

En este sentido no podemos obviar, y más en el ámbito territorial que nos ocupa, la Sentencia 603/2014, de la Sala de lo Contencioso Administrativo del Tribunal Superior de Justicia del País Vasco que ha venido a validar estas cláusulas sociales, recordando la acomodación al derecho comunitario de las mismas amparadas por el artículo 118.1 del Texto Refundido de la Ley de Contratos del Sector Público, con referencia a la Directiva 2004/18/CE del Parlamento y el Consejo, de 31 de mayo; y respecto a los trabajadores desplazados de un estado miembro a otro, la Directiva 96/71/CE, con su trasposición al derecho español interno mediante la Ley 45/1999, de 29 de noviembre.

La Sentencia viene a validar la Norma Foral de las Juntas Generales de Gipuzkoa 4/2013, de 17 de julio, de incorporación de cláusulas sociales en los contratos de obra del Sector Público Foral; frente

10.- No obstante, este criterio ya se venía manteniendo desde el 2001. Así, la Comunicación Interpretativa de la Comisión, de 15 de octubre de 2001, COM (2001) 566 final, ya señalaba la viabilidad de integrar aspectos sociales en la legislación comunitaria de contratos públicos.

11.- Hemos de recordar que, aunque existen dos anteproyectos de Ley (para contratos del sector público y para contratos en los "sectores especiales"), y a pesar de haberse superado el plazo de transposición sin que ésta se haya producido, varios preceptos de las Directivas de contratación pública tienen efecto directo y desplazan algunas normas reguladoras españolas. En este sentido, si bien es cierto que la Ley de contratos futura permanece en espera, debe tenerse en cuenta que el Consejo de Estado ya emitió el preceptivo dictamen en sesión celebrada el 10 de marzo de 2016 - $n^{0}$ 1/116/2015- (Nota redactada en revisión posterior a la entrega del artículo). 
a las tesis de la Autoridad Vasca de la Competencia que, procesalmente representada por los servicios jurídicos del Gobierno Vasco, entendía que la norma no encontraba acomodo en la libre competencia. Y así se alegaba por la citada Autoridad al entender que se imponían obligaciones a las empresas adjudicatarias que además de, en este caso vulnerar la normativa laboral y comunitaria, generaban un sobrecoste en las empresas de quieran pretendieran acceder a los contratos públicos vulnerando, según se alegaba de parte, la libre competencia en el mercado.

Sin embargo, y como ya hemos indicado, el Tribunal ha entendido que la Disposición Foral no restringe la competencia en el mercado de las licitaciones, amparando la validez de la Normal Foral citada y, por extensión, las cláusulas sociales ${ }^{12}$.

\section{3.- La Economía Social}

\subsection{La Economía Social en Europa}

Desde hace más de 20 años, las Instituciones Europeas han reconocido en diversos documentos la capacidad de la Economía Social para generar desarrollo económico y cohesión social en Europa ${ }^{13}$. Así, el Consejo, la Comisión Europea, el Parlamento Europeo y el Comité Económico y Social Europeo (CESE) han ido definiendo a este sector económico como un actor económico y social cuya contribución resulta decisiva para la generación de valor añadido social y para resolver algunos de los desafíos y desequilibrios más importantes de la sociedad europea, consolidando su bienestar y el modelo social europeo.

El Parlamento Europeo ha destacado además, en su Resolución de 19 de febrero de 2009, sobre Economía Social que "la economía social pone en evidencia un modelo de empresa que no se caracteriza por el tamaño o el sector de actividad sino por el respeto de valores comunes como la primacía de la democracia, de la participación de los actores sociales y de la persona y del objeto social sobre el beneficio individual; la defensa y la aplicación de los principios de solidaridad y de respon-

12.- En concreto, el artículo 4.2 de la Norma Foral 4/2013 señala que "En el anuncio de licitación así como en la carátula de los pliegos de cláusulas administrativas particulares de los contratos de obras deberá incluirse un subapartado en el que se indique que dicha contratación estará sometida al cumplimiento de condiciones especiales de carácter social", condiciones que luego concretan no sólo en relación a las condiciones generales de cumplimiento de las obligaciones de carácter social y seguridad social en el trabajo, sino en particular en lo establecido en un convenio colectivo particular; remisión ésta con la que la Institución Foral buscaba blindar unas condiciones de los trabajadores de las empresas adjudicatarias y por ende su no precarización laboral.

13.- La Comisión Europea calcula que en la Unión Europea existen dos millones de empresas de economía social, que suponen el 10\% del total del tejido empresarial y emplean a 11 millones de personas, 10 que equivale al $6 \%$ de la población activa de la UE. Cf.:http://ec.europa.eu/enterprise/policies/sme/promoting-entrepreneurship/social-economy/). 
sabilidad; la conjunción de los intereses de los miembros usuarios con el interés general; el control democrático ejercido por los miembros; la adhesión voluntaria y abierta; la autonomía de gestión y la independencia respecto de los poderes públicos ${ }^{14}$, y la asignación de lo esencial de los excedentes al servicio de la consecución de objetivos como el desarrollo sostenible, el interés de los servicios a los miembros y el interés general".

Siguiendo con las referencias de Instituciones europeas, el Comité Económico y Social Europeo en su Dictamen sobre el Plan Europeo de Recuperación Económica señaló que la Economía Social "se caracteriza por ofrecer respuestas innovadoras a las necesidades sociales, conjugando rentabilidad y solidaridad, generando empleos de calidad, reforzando la cohesión social y territorial, vinculando producción y desarrollo sostenible; potenciando, en definitiva, el ejercicio de la ciudadanía activa y de la responsabilidad social empresarial".

Estos reconocimientos generales hacen que el sector público haya empezado a mirar a estas empresas ya no sólo como un simple observador, sino como posibles gestores a la hora de la prestación de sus servicios propios, y más en concreto en sectores en los que ya está implantada la economía social desde hace décadas como son, además de otros, los servicios sociales y de la salud; todo ello en el marco -como hemos visto- de entidades que se caracterizan por la búsqueda del interés común.

Pero la referencia de futuro ha sido plasmada por el propio Parlamento Europeo cuando reconoce que las Entidades de la Economía Social son "una de las piedras angulares de un modelo social europeo para el futuro debería ser la economía social o tercer pilar, donde se incluyen las cooperativas, mutualidades, asociaciones y fundaciones, que constituyen una parte estructural del propio modelo (...), y son un factor de desarrollo, sostenibilidad y eficiencia en el futuro"15.

Además de por su aportación en lo que a la creación de empleo, inclusión social e igualdad de oportunidades se refiere, se ha reconocido que los agentes de la Economía Social desempeñan una importante función a la hora de integrar el apoyo a las familias y a la tercera edad. Son numerosas las organizaciones de la Economía Social dedicadas a la prestación de servicios a las personas dependientes, a las que se les debe considerar como interlocutor privilegiado para el desarrollo de las políticas públicas, puesto que estas empresas responden a necesidades de la ciudadanía y facilitan la mejora de la calidad de vida.

En este marco de atención y reconocimiento por parte de las Instituciones Públicas, encontramos una línea de desarrollo en el marco de la Economía Social como es la de las Empresas Sociales ${ }^{16}$, las cuales han tomado especial protagonismo en los últimos años en el reiterado ámbito socio-sani-

14.- No puede confundirse esta idea con el hecho que los propios poderes públicos no fomenten e incluso participen en las Entidades de la Economía Social.

15.- (Resolución del Parlamento Europeo sobre un modelo social europeo para el futuro (2005/2248(INI))

16.- Vid. el punto referido a las Empresas Sociales. 
tario, recurriendo estos novedosos proyectos a la evaluación social, la concesión de distintivos éticos y medioambientales y a las adquisiciones públicas en sus respectivos ámbitos de actividad.

\subsection{La Economía Social en España ${ }^{17}$}

Hasta hace poco tiempo el marco de la Economía Social en España no estaba definido. Ha sido la Ley 5/2011, de 29 de marzo, de Economía Social la que ha venido a clarificar la situación, definiendo este sector en su artículo 2 como "las actividades económicas y empresariales, que en el ámbito privado llevan a cabo aquellas entidades que, de conformidad con los principios recogidos en [dicha ley], persiguen bien el interés colectivo de sus integrantes, bien el interés general económico o social, o ambos".

Lo que resulta novedoso en lo que hace referencia a la clarificación del sector económico ha sido que por fin se han establecido los fundamentos que definen a las Entidades que lo conforman, como son:

a) Primacía de las personas y del fin social sobre el capital, que se concreta en gestión autónoma y transparente, democrática y participativa, que lleva a priorizar la toma de decisiones más en función de las personas y sus aportaciones de trabajo y servicios prestados a la entidad 0 en función del fin social, que en relación a sus aportaciones al capital social.

b) Aplicación de los resultados obtenidos de la actividad económica principalmente en función del trabajo aportado y servicio o actividad realizada por las socias y socios o por sus miembros y, en su caso, al fin social objeto de la entidad.

c) Promoción de la solidaridad interna y con la sociedad que favorezca el compromiso con el desarrollo local, la igualdad de oportunidades entre hombres y mujeres, la cohesión social, la inserción de personas en riesgo de exclusión social, la generación de empleo estable y de calidad, la conciliación de la vida personal, familiar y laboral y la sostenibilidad.

Como última mención diremos que el artículo 5 establece las tipologías de organizaciones que conforman la Economía Social. A saber: cooperativas, mutualidades, fundaciones, asociaciones que lleven a cabo actividad económica, sociedades laborales, empresas de inserción, centros especiales de empleo, cofradías de pescadores y sociedades agrarias de transformación; sin olvidar que la

\footnotetext{
17.- Sobre la Economía Social en España no cabe más que remitirse a toda la labor investigadora que se desarrolla en Ciriec-España (www.ciriec.es) y que periódicamente, y desde hace años, se plasma en su Revista tanto general como jurídica.

18.- En 2008 la Economía Social en España estaba integrada por más de 200.000 entidades, 24 millones de socios, 1,2 millones de empleos directos y 116.000 millones de euros de facturación, con una aportación del 2,47\% del PIB. (Informe CIRIEC "Las Cifras clave de la Economía Social en España").
} 
propia Ley $5 / 2011$ contempla la posibilidad de incorporar nuevas tipologías de entidades que serán incluidas en el Catálogo de Entidades de la Economía Social que gestionará el Ministerio de Trabajo e Inmigración ${ }^{18}$.

Definida la Economía Social, hemos de poner de manifiesto que el sector público no es ajeno a este sector económico y puede no sólo participar en el mismo de diferentes formas y con las consecuencias jurídicas que se deriven de tal participación, sino que incluso puede, y como veremos más tarde, convertirse en promotor de algunas estas entidades.

\section{4.- Por qué elegir la sociedad cooperativa como instrumento de gestión de los servicios públicos: las ventajas del modelo en el caso vasco}

La Cooperativa es una forma de organización empresarial basada en la estructura y funcionamiento democráticos. Su actividad se desarrolla atendiendo a los principios cooperativos, aceptados y regulados en los ámbitos autonómico, estatal e internacional: la adhesión voluntaria y abierta de los socios (puerta siempre abierta), la gestión democrática (una persona=un voto), la participación económica de los socios (participación en los beneficios en función del trabajo del socio y no de su capital), la educación, formación e información (escuela de democracia económica) y el interés por la comunidad (desarrollo sostenible y compromiso democrático con lo local).

La vigente Ley 4/1993, de 24 de Junio, de Cooperativas establece una serie de clases de este tipo societario, entre las que podemos encontrar las cooperativas de trabajo asociado, consumo, enseñanza, agrarias, explotación comunitaria, viviendas, financieras, sanitarias, servicios e integración social; pudiendo a nuestro entender aglutinarse todas ellas -como así lo ha puesto de manifiesto la doctrina- en dos grandes grupos: las cooperativas de trabajo asociado y las de consumo.

Pero hemos de acometer a continuación la exposición del por qué le puede interesar al sector público que determinados servicios, que en nuestro caso se concretan en el ámbito sociosanitario, se presten a través ya no de una Entidad de la Economía Social, sino específicamente a través de una Cooperativa.

Pues bien, si por algo se caracteriza el modelo cooperativo es por recoger en su seno una serie de valores y normas de comportamiento ético que deben guiar a los cooperativistas en la toma de decisiones, tanto en las tareas de gobierno interno (órganos sociales, órganos directivos y de gestión, 
socios/as), como externo (relaciones con grupos de interés, trabajadores, clientes, proveedores, instituciones y sociedad en general).

Pero estos valores, que se pueden apreciar en conocidos modelos en el País Vasco, tienen su plasmación concreta en todas y cada una de las acciones que se nos presentan en la Cooperativa, y en particular en los cuatro ámbitos de actuación siguientes: los órganos sociales, órganos directivos y de gestión, los socios y la propia sociedad. Lo que no cabe duda es que algunos de estos valores, como por ejemplo la veracidad y transparencia en todas las actuaciones; la visión empresarial y a largo plazo; la responsabilidad, compromiso e implicación con la cooperativa; la cooperación y trabajo en equipo entre los socios; y la lealtad con los clientes, proveedores e instituciones, son aspectos genéricos que luego tienen su concreción en una serie de comportamientos que definen igualmente el modelo cooperativo.

Siguiendo el Código de Buen Gobierno elaborado por la Federación de Cooperativas de Trabajo Asociado, Enseñanza y Crédito de Euskadi (Vitoria, 2011), básicamente siguiendo las experiencias más exitosas de sus Cooperativas Industriales y de Servicios, podemos diferenciar los cuatro ámbitos de actuación ya señalados a la hora de analizar sus valores y su comportamiento:

En relación a los órganos sociales de la Cooperativa:

- Nos encontramos con la Asamblea General como expresión más genuina de la gestión democrática, integrada por todos los socios y soberana en las decisiones que adopta, y en donde en principio opera, como ya hemos visto, el histórico principio de "una persona un voto".

- El Consejo Rector, es el órgano de dirección y gestión de la Cooperativa, obedeciendo a la necesidad de adecuar la entidad a las exigencias derivadas del mundo competitivo en el que se mueve el mercado, debiéndose dotar de personal cualificado en la búsqueda del interés común, y atendiendo a las diferentes variables socioeconómicas y empresariales.

- Una de las características principales de los órganos sociales de la Cooperativa se concreta en el derecho de información que tienen los socios (regulado ampliamente en la Ley 4/1993), así como en la trasparencia y veracidad de todas sus actuaciones; sin olvidar la debida lealtad de los miembros del Consejo Rector al colectivo de socios, quienes en todo momento les podrán remover de sus cargos.

- Los órganos sociales en un proyecto participativo están orientados al desarrollo de las personas y a su participación activa, promoviendo para ello una cultura autogestionaria, el desarrollo profesional y la promoción interna. 
- La Cooperativa, y en concreto sus órganos sociales, se caracterizan por promover y salvaguardar la igualdad y la equidad, garantizando a todos el derecho al sufragio tanto activo como pasivo, la distribución de la riqueza siempre de forma proporcional a la actividad cooperativizada desarrollada, en la lucha contra el absentismo laboral y en la conciliación familiar.

- Las cooperativas, a diferencia de otros modelos empresariales -incluso del resto de familias de la Economía Social-, presentan órganos sociales que ayudan a la gestión transparente y democrática de la sociedad. Así, la Comisión de Vigilancia es el órgano -de carácter interno y elegido por la Asamblea General- responsable de certificar la veracidad de las cuentas, la situación económica de la Cooperativa, la supervisión de la legalidad de todos los acuerdos sociales y la documentación social de la sociedad. Por otro lado, el Consejo Social es el órgano representativo de los socios en materia laboral, siendo sus funciones la información y el asesoramiento, participando de manera activa en las decisiones laborales de la sociedad. Por último, el Comité de Recursos, también elegido por la Asamblea General, tiene como misión ejercer de segunda instancia o de revisarlos acuerdos disciplinares y sancionadores de la Cooperativa, así como cualquier tipo de acuerdo de los diferentes órganos sociales, buscando siempre la ecuanimidad y la justicia.

En relación específicamente al órgano de dirección y gestión de la Cooperativa, su actuación debe estar enmarcada en la integración en la gestión diaria de los valores y principios de la Entidad, coordinando los diferentes niveles y órganos en la toma de decisiones según sus competencias. $Y$, además, esto se desarrolla desde el ejercicio del liderazgo en el marco de una entidad caracterizada por los valores de la atención a las personas, la flexibilidad, el desarrollo y la cultura de la participación.

El tercer ámbito que queremos destacar es el referente a la activación de los socios (el componente humano) en el proyecto empresarial, dejando constancia que la incorporación al proyecto implica la adhesión al mismo en el marco del hecho diferencial cooperativo, lo que conlleva una identificación con los principios, valores y objetivos; al tiempo que se activa el socio no solamente en la obligación de la realización de la actividad cooperativizada, sino también en la participación activa, crítica y positiva en el proyecto; sin olvidar la asunción de los cargos para los que fuera elegido como máxima materialización de la participación en el hecho empresarial.

Por otro lado, señalaremos que la Cooperativa se mueve en un entorno económico y social cambiante y que requiere múltiples relaciones, por lo que deberá fomentar la lealtad con clientes y proveedores reconociendo su posicionamiento en el mercado, facilitar la integración de los trabajadores por cuenta ajena -si los hubiera-, la intercooperación y alianzas con otras cooperativas principalmente de su ámbito sectorial y en la búsqueda de información, los proyectos compartidos y buenas prácticas empresariales, sin olvidar la integración -sobre todo en el caso que nos ocupa- de la propia Administración Pública en su proyecto. 
Además, no podemos obviar cómo la Cooperativa apuesta por una política no sólo de crecimiento, sino también de desarrollo, contribuye al desarrollo sostenible medioambiental, crea y mantiene empleo de calidad y más estable que otras fórmulas empresariales, y aplica los Fondos Sociales -de obligada dotación- a destinos orientados a impulsar valores y desarrollos económicos, sociales y culturales que repercutan en toda la comunidad donde está ubicada.

Por último, el movimiento cooperativo vasco tiene unas señas de identidad reconocidas vinculadas con la calidad, las buenas prácticas, la profesionalidad, el prestigio, su compromiso con el desarrollo de la sociedad vasca, etc. y que se extienden como garantía al conjunto de sus actividades y servicios que a lo largo de su historia ha ido desarrollando. Al menos así se lo reconocen los agentes consultados para los que el movimiento cooperativo constituye un agente socioeconómico de relevancia en el País Vasco que debería ocupar también un papel destacado en el desarrollo de la atención a la dependencia.

En este contexto de práctica empresarial, atendiendo al ámbito sociosanitario, y más en concreto al de la Dependencia, en los últimos años se ha venido dando no sólo un reconocimiento explícito del apoyo a las sociedades cooperativas, sino que también los propios responsables de la planificación y organización de los servicios públicos vascos ven un mercado natural de intervención para el movimiento cooperativo vasco derivado de su naturaleza no lucrativa, sus principios inspiradores y el proyecto social en cuanto empresa.

Los servicios sociosanitarios presentan un escenario de atención cada vez más exigente en cuanto a niveles de profesionalización y calidad en la atención, y la calidad del empleo es un hecho destacado del movimiento cooperativo y en el que aparecen distintos elementos que contribuyen a otorgarle ventajas comparativas frente a otro tipo de entidades. Estas son la implicación de los trabajadores con el objeto social, lo que supone una menor rotación de los equipos; la mejora de las condiciones laborales, por tanto, menor conflictividad laboral; la profesionalización de la intervención, mejorando así la calidad del servicio; y la formación como instrumento para la mejora continua.

No queremos terminar este punto sin apuntar dos garantías del modelo vinculadas en esta ocasión con el sector público: el Registro y el Arbitraje cooperativo.

Las sociedades cooperativas disponen de un Registro propio de carácter administrativo incardinado en el actual Departamento de Empleo y Políticas Sociales, y regulado por el Decreto 59/2005, de 29 de marzo, por el que se aprueba el Reglamento de organización y funcionamiento del Registro de Cooperativas de Euskadi.

El Reglamento ordena este Registro adaptándolo a la Ley 4/1993, dotando al hecho registral de una gran seguridad jurídica, imprescindible en el tráfico empresarial en el que se mueven las sociedades cooperativas. La Norma establece como líneas fundamentales, la basada en la definición del Registro de Cooperativas de Euskadi como un registro jurídico con eficacia jurídica privada respecto 
a las sociedades cooperativas (muy superior en cuanto exigencia por ejemplo al de Asociaciones 0 Fundaciones -también de carácter administrativo-), y otra basada en su vinculación dentro de la organización administrativa de la Comunidad Autónoma Vasca. Es indudable que la garantía registral por ejemplo de la necesaria inscripción de los administradores como garantía en el tráfico jurídico; 0 de los depósitos de cuentas, cuestión ésta que no se aprecia por ejemplo en las asociaciones con actividad económica, es una garantía no sólo para la Administración Pública, sino también para los terceros interesados que contratan con la Cooperativa para poder tener así conocimiento de la actividad económica que se desarrolla en el seno de la sociedad.

Al mismo tiempo, las sociedades cooperativas disponen en sede pública, y más en concreto en el Consejo Superior de Cooperativas de Euskadi de un servicio de resolución de conflictos como es el Servicio Vasco de Arbitraje Cooperativo ${ }^{19}$, único de carácter público y relativo al derecho de sociedades en todo el Estado.

El Servicio Vasco de Resolución Extrajudicial de Conflictos en Cooperativas -SVAC- del Consejo Superior de Cooperativas de Euskadi es la entidad encargada de la administración de los diferentes procedimientos de resolución de conflictos en las cooperativas vascas. Conoce las cuestiones litigiosas que se susciten entre las cooperativas, entre éstas - 0 sus diferentes órganos sociales- y sus socios, 0 en el seno de las mismas entre sus diferentes órganos sociales o entre los socios. Así mismo, fomenta las medidas para la prevención de los conflictos en las cooperativas vascas y atiende a las necesidades de formación en la resolución de los mismos que puedan desprenderse del propio sector cooperativo.

La posibilidad de que los conflictos no se judicialicen y tengan una respuesta rápida, profesional y especializada en cuanto a su resolución, y que con carácter gratuito se configura como un servicio público, hacen de la fórmula cooperativa especialmente atractiva en la actualidad como fórmula de gestión de cualquier actividad o prestación de servicios (incluidos los públicos).

\section{5.- La promoción de las Cooperativas por los poderes públicos (particular referencia a la Comunidad Autónoma del País Vasco). Las cooperativas de Utilidad Pública y las Cooperativas de Interés Social}

Señala el artículo 129.2 de la Constitución española que "Los poderes públicos promoverán eficazmente las diversas formas de participación en la empresa y fomentarán, mediante una legislación adecuada, las sociedades cooperativas. También establecerán los medios que faciliten el acceso de los trabajadores a la propiedad de los medios de producción". 
El artículo 129.2 ha sido, hasta la fecha, objeto de escasa atención por el Tribunal Constitucional. Sin embargo, sí podemos citar la Sentencia del citado Tribunal 77/1.985, de 27 de junio, en la que los recurrentes estimaban discriminatoria la preferencia, a la hora de regular los criterios generales de prelación en el establecimiento de conciertos económicos, a favor de centros docentes constituidos bajo la fórmula cooperativa. Ahora bien, ha de tenerse en cuenta que tal preferencia era, por así decirlo, de segundo grado, porque actuaba en segundo lugar y siempre después de atenderse al primer criterio relativo a la satisfacción de las necesidades de escolarización que atiendan a poblaciones escolares de condiciones socioeconómicas desfavorables o que, además, realicen experiencias de interés pedagógico. Sobre esta cuestión, estableció el Tribunal Constitucional que "La preferencia a favor de los Centros en régimen de cooperativa se produce sólo entre los que cumplan con las finalidades señaladas, y no fuera de éstas. Y ello no es más que el desarrollo del mandato contenido en el artículo 129, número 2, que compromete al legislador a fomentar, mediante una legislación adecuada, las sociedades cooperativas, con lo que la diferencia de trato introducida tiene fundamento constitucional expreso, por lo que no puede ser tachada de irrazonable"20.

Esta referencia nos lleva a legitimar, como vemos, actuaciones discriminatorias a favor de las sociedades cooperativas, también en el ámbito socio-sanitario, y más si cabe si nos encontramos con cooperativas de utilidad pública.

Abordando la realidad en la Comunidad Autónoma del País Vasco, el artículo 137 de la Ley 4/1993, establece que los poderes públicos de la Comunidad Autónoma del País Vasco asumen como función de interés social la promoción, estímulo y desarrollo de las entidades cooperativas y sus estructuras de integración empresarial y representativa, estimulando la creación de cooperativas con esa finalidad, y contando a tal fin con la colaboración del Consejo Superior de Cooperativos de Euskadi. Además, continúa el citado artículo estableciendo que las entidades cooperativas que contribuyan a la promoción del interés general de Euskadi mediante el desarrollo de sus funciones serán reconocidas de utilidad pública por el Gobierno Vasco.

En este marco de proteccionismo, el artículo $138^{21}$ de la misma Ley, establece las medidas de fomento entre las que cabe destacar, por ejemplo, que las cooperativas de trabajo asociado y las de segundo o ulterior grado que las agrupen tendrán derecho preferente en los casos de empate en las ofertas correspondientes a los concursos y subastas en que participen y que sean convocados por las Administraciones Públicas y entes de ellas dependientes para la realización de obras, servicios y suministros; siguiendo con ello la tendencia jurisprudencial ya expuesta.

20.- Sobre una mayor interpretación del artículo 129.2 de la Constitución española, vid., principalmente, PAZ CANALEJO, Narciso, "La Constitución y las Cooperativas", Documentación Administrativa, 1980, núm. 186; PRADOS DE REYES, F.J. y VIDA SORIA, J. "Comentarios al artículo 129. La participación social en el texto de la Constitución", en Comentarios a las Leyes Políticas y Constitución de 1.978; y PULIDO QUEVEDO, Manuel, "La Constitución española", Pamplona, 1.986, págs. 1.583 y ss.

21.- Sobre el resto de medidas de fomento cotéjese el artículo 138, y más en concreto las que hacen referencia a las cooperativas de consumo, agrarias o de viviendas. 
El Decreto 64/1999, de 2 de febrero, del Gobierno Vasco aprobó el Reglamento sobre procedimientos y requisitos para que las sociedades cooperativas pudieran ser calificadas de utilidad pública, como elemento diferenciador del carácter de aquellas entidades cooperativas que contribuyan al interés general de Euskadi.

En efecto, en el Título III, regulador de las relaciones entre las Cooperativas y la Administración, y concretamente en el art. 137.2 de la Ley 4/1993 se establece que las entidades cooperativas que contribuyan a la promoción del interés general de Euskadi mediante el desarrollo de sus funciones serán reconocidas de utilidad pública por el Gobierno Vasco, por lo que en el citado Decreto se procedió a la determinación de un procedimiento tasado de cara a su reconocimiento.

Dicho reconocimiento de la condición de utilidad pública significa para la Cooperativa un resorte de gran interés para sus posibilidades fácticas de desenvolvimiento, acceso a la ayuda y protección institucionales, y, con ello, para el servicio que el movimiento cooperativista presta, no sólo a sus asociados, sino también a la sociedad en general.

Entrando en los requisitos para acceder a dicha calificación, podrán acceder al mismo las sociedades cooperativas que contribuyan mediante el desarrollo de sus funciones a la promoción del interés general de Euskadi y a estos efectos, se entiende que sirven al interés general de Euskadi aquéllas en cuyo objeto social sean primordiales los siguientes fines: asistencia social, cívicos, educativos, culturales, científicos y de investigación, deportivos, sanitarios, de cooperación para el desarrollo, defensa del medio ambiente, fomento de la economía social, fomento de la paz social y ciudadana, o cualesquiera otros fines de naturaleza análoga.

Los beneficios para las Cooperativas declaradas de utilidad pública son -siguiendo lo establecido por el propio Decreto 64/1999- además de la utilización de dicha declaración en todos sus documentos a continuación del nombre de la Entidad, el disfrute de las exenciones, bonificaciones, subvenciones y demás beneficios de carácter económico, fiscal y administrativo que en cada caso se acuerden.

Podrán ser declaradas de utilidad pública aquellas que, en el marco de la actividad ya definida, además carezcan de ánimo de lucro. A estos efectos serán consideradas como sociedades cooperativas sin ánimo de lucro las que en sus Estatutos recojan expresamente que los resultados positivos que se produzcan en un ejercicio económico no podrán ser distribuidos entre sus socios; que las aportaciones de los socios al capital social, tanto obligatorias como voluntarias, no podrán devengar un interés superior al interés legal del dinero, sin perjuicio de la posible actualización de las mismas; que el desempeño de los cargos del Consejo Rector sea con carácter gratuito, sin perjuicio de las compensaciones económicas procedentes de los gastos en los que puedan incurrir los Consejeros en el desempeño de sus funciones; y que las retribuciones de los socios trabajadores, 0 , en su caso, de los socios de trabajo y de los trabajadores por cuenta ajena no podrán superar el ciento cincuenta por ciento de las retribuciones que en función de la actividad y categoría profesional, establezca el Convenio colectivo aplicable al personal asalariado del sector. 
Existen otros requisitos que si bien se nos presentan como tangenciales sí deben ser necesariamente referenciarlos. Así, los otros dos requisitos son en primer lugar que se encuentren constituidas y debidamente inscritas en el Registro de Cooperativas de Euskadi, en funcionamiento y dando cumplimiento efectivo a sus fines estatutarios, de forma ininterrumpida durante al menos dos años inmediatamente anteriores a la fecha de presentación de la solicitud de declaración de utilidad pública; y en segundo lugar que en el caso de ser titulares, directa o indirectamente, de participaciones mayoritarias en sociedades mercantiles, acrediten ante el Departamento, en este caso de Empleo y Políticas Sociales, la existencia de dichas participaciones, así como que la titularidad de las mismas coadyuva al mejor cumplimiento de los fines de la Cooperativa.

Parece más que evidente que se abre un importante camino de colaboración entre la Administración Pública y las Cooperativas, bien ya existentes o constituidas ex novo, y que declaradas de utilidad pública puedan prestar servicios sociosanitarios con los beneficios administrativos que se pudieran determinar.

Esta calificación puede dar lugar, incluso, y de acuerdo con los beneficios administrativos a los que alude el Decreto, a adjudicaciones públicas directas 0 a beneficios en los concursos públicos (a través de cláusulas sociales) para este tipo de entidades, en relación a determinados bienes o servicios, si bien y por seguridad jurídica hubiera sido conveniente concretar estos beneficios administrativos con rango de desarrollo del propio Decreto22.

Por otro lado, y relacionado con el ámbito principal que nos ocupa, el sociosanitario, el Decreto 61/2000, de 4 de abril, por el que se regulan las Cooperativas de Iniciativa Social, establece en su Exposición de Motivos que entre las necesidades sociales a las que dan respuesta las cooperativas vascas de Trabajo Asociado sobresalen de forma creciente las que desarrollan su actividad en el ámbito de prestación de servicios sociosanitarios, educativos, culturales o medioambientales. Pues bien, estas Cooperativas han desarrollado en este ámbito unos comportamientos y reglas societarias internas específicas, caracterizadas básicamente por (al igual que las de Utilidad Pública) la ausencia de ánimo de lucro, y que son conocidas como cooperativas "de Iniciativa Social".

El Decreto 61/2000 estableció unas condiciones de idoneidad para obtener la calificación y evitar la inseguridad jurídica que en su momento podría derivarse de la indefinición de su marco de actuación, referido tanto a las actividades que componen su objeto social como a su caracterización social interna, fundamentalmente derivada de la ausencia de ánimo de lucro ${ }^{23}$, cuyos requisitos para su constatación son los ya apuntados para las Cooperativas de utilidad pública.

22.- En este sentido, caber destacar que la mayoría de las ikastolas vascas conformadas bajo la fórmula cooperativa -y lo son prácticamente todas- han ido obteniendo la calificación de utilidad pública lo que las equipara prácticamente a la Euskal Eskola Publikoa. 


\section{6.- Experiencias internacionales en el cooperativismo sanitario}

\subsection{Un recorrido general}

En muchos países industrializados, las cooperativas de salud (en su sentido más amplio) han surgido como mecanismo alternativo de provisión de servicios sanitarios.

Así, en los años 60 en Japón, unas 6.000 cooperativas agrícolas proveían servicios sanitarios subvencionados por el gobierno a sus miembros. El fenómeno siguió creciendo como consecuencia de la falta de servicios sanitarios adecuados, sobre todo para las comunidades de bajos ingresos que no se podían permitir el acceso a estructuras de sanitarias, ni públicas ni privadas.

En algunos países europeos, al igual que ocurrió en Estados Unidos y Canadá, las cooperativas se constituyeron en algunos casos como respuesta al encarecimiento de costes en el sector sanitario; en otros casos, como consecuencia de las deficiencias en la prestación de servicios sanitarios, especialmente en el caso de los ancianos.

Por tipología, las cooperativas propiedad de proveedores se han desarrollado extensamente en países como Brasil. La cooperativa Unimed, considerada una de las mayores cooperativas médicas del mundo, congrega a unos 109.000 médicos cooperativistas, ofreciendo sus servicios a 18 millones de personas.

En Europa, Italia es otro de los grandes exponentes del movimiento cooperativo médico a nivel internacional, donde se estima que alrededor del 13\% del gasto público en asistencia sanitaria y social se destina a financiar los servicios prestados por las cooperativas. Otros países como Suecia, Finlandia Alemania o Portugal han incorporado también cooperativas médicas a su contexto sanitario, si bien su desarrollo ha sido muy inferior a los países citados.

23.- Estas Cooperativas no pueden confundirse con las de Integración Social a las que se refiere el artículo 127 de la Ley 4/1993. Este artículo establece que las Cooperativas de integración social estarán constituidas, al menos mayoritariamente, por disminuidos físicos o psíquicos, y podrán basarse en el trabajo asociado para organizar, canalizar y comercializar los productos y servicios del trabajo de los socios o ir dirigidas a facilitar la provisión de bienes y servicios de consumo general o específicos. En estas Cooperativas podrán participar como socios entidades públicas responsables de la prestación de cualesquiera servicios sociales mediante la correspondiente aportación y la designación de un representante de las entidades públicas. Este representante prestará su trabajo personal de asistencia técnica, profesional y social junto a los socios de la cooperativa y asistirá con voz a las reuniones de todos los órganos sociales. 
En España, existe un tipo de cooperativa de proveedores en el que los miembros son médicos y propietarios y proveen servicios sanitarios a un colectivo específico de clientes, que contratan los servicios a dicha cooperativa a través de distintas fórmulas contractuales. Es un tipo de cooperativa promovida por parte de sus propietarios, los proveedores, pero orientada al usuario-cliente; es una especie de "cooperativa sanitaria integrada" formada por tres cooperativas: una cooperativa de trabajo de médicos que agrupa 5.000 socios, "Autogestión Sanitaria Sociedad Cooperativa"; una cooperativa de consumo, la "Sociedad Cooperativa de Instalaciones Asistenciales" y una cooperativa de médicos de ámbito estatal de segundo nivel denominada "Lavinia Sdad. Cooperativa" que agrupa a más de 20.000 médicos. Las tres cooperativas formaron en 1989 la Fundación Espriu con el objeto de promover el cooperativismo sanitario24.

En relación a las cooperativas de usuarios, Canadá y Estados Unidos, junto con Japón, son los países que mayor tradición tienen a nivel mundial. Así, en Estados Unidos, por ejemplo, habitualmente adoptan la forma de aseguradoras de salud, y sirven a una población de unos 4 millones de personas.

Las dos organizaciones más representativas son "Healthpartners" (nacida en 1957) y "Group Health Cooperative" (GHC) (fundada en 1947), que ocupan el primer y segundo lugar respectivamente en el sector de las cooperativas de salud a nivel mundial por volumen de negocio. Las dos cooperativas sirven a una población de unos 500.000 usuarios aproximadamente. Ofrecen asistencia sanitaria a través de una red de proveedores del ámbito de atención primaria y de la atención hospitalaria. Así, el GHC está basado en un modelo que combina grupos de práctica multidisciplinar y una red de proveedores de la comunidad. Está basado en un sistema integrado a nivel asistencial y financiero; uno de sus pilares fundamentales es el modelo de atención primaria centrado en el paciente que promueve los equipos de trabajo multiespecialidad para la provisión de cuidados proactivos y coordinados, facilitado por un potente sistema de información que permite la interacción entre profesionales y entre profesionales y pacientes. Ambas cooperativas son organizaciones integradas referentes en la gestión de la cronicidad a nivel internacional que ofrecen servicios y cuidados de alto valor añadido al paciente.

\subsection{La experiencia del Reino Unido en la externalización de los servicios sanita- rios y de Cuidado}

La remisión por parte de los países anglosajones, y muy especialmente del Reino Unido, al llamado Tercer Sector en lo que a la gestión de servicios sociosanitarios hace referencia, nos ha llevado a detenernos, siquiera brevemente, en el trabajo de investigación "Bases para un plan estratégico

24. - Es imposible hablar del cooperativismo sanitario en España y no hacerlo del proyecto fundado por el Doctor Jopep Espriu, la Fundación que lleva su nombre y mantiene su legado (www.fundaciónespriu.coop), y la revista "Compartir" a cuyos todos sus números nos remitidos para profundizar en esta determinante experiencia autogestionaria (www.fundacionespriu.coop/publicaciones-2). 
de la Economía Social" realizado en 2008 y que pudimos dirigir para la EUROPEAN FOUNDATION FOR PUBLIC POLICIES - EZAI FUNDAZIOA, sin perjuicio de dejar constancia de forma clara de las notables diferencias existentes con el mundo jurídico latino.

En el Reino Unido, y frente al capitalismo popular impulsado por Margaret Thatcher nació la denominada "Tercera Vía" como reformulación de la socialdemocracia llevada a cabo por el laborismo de Tony Blair. Sin embargo, ambas corrientes convergían en la privatización del ámbito económico y en la asunción por parte pública del ser garante del desenvolvimiento óptimo de los mercados, buscando con ello la superación de las rigideces de un sector público poco eficiente mediante un profundo proceso privatizador. Sin embargo, las aproximaciones a esta idea se planteaban -todavía hoy- desde presupuestos bien distintos.

Pero seguramente el cambio de mayor envergadura tuvo lugar en la mentalidad de las personas, las cuales pasaron de ser ciudadanos pasivos a tomar de nuevo las riendas de su futuro económico. Activación que se pretende ahora en el sur de Europa motivada por la crisis económica y, más en concretamente, en cuanto su afección a los servicios públicos se refiere.

Es en este marco cuando nace el concepto británico del Estado social inversor. Es decir, el Estado, a través de sus inversiones en distintos ámbitos, crea las infraestructuras necesarias y fomenta el capital humano de todos sus ciudadanos en aras a que ellos mismos sean los que generen una mayor riqueza y las estructuras que garanticen una mayor cohesión social (llámese capital social).

Lo que nos debe interesar no es tanto la teorización sobre el proceso de privatización en el Reino Unido, sino su materialización o no a través de Empresas de la Economía Social. Pues bien, como primera aproximación diremos que el concepto de "Economía Social" ni se entiende, ni se reconoce, y por lo tanto ni se denomina, en la tradición anglófona, de la misma manera que en la tradición francófona. Este concepto no es asumido ni por las autoridades públicas, ni por el mundo académico, ni por las propias organizaciones y empresas que componen el sector. En lugar de dicho concepto, los conceptos afines de mayor aceptación son Empresa Social (Social Enterprise), Tercer Sector (ThirdSector Organizations), o Sector No lucrativo o Sin Ánimo de Lucro (Non-Profit Sector).

La escuela anglosajona ha optado por emplear el concepto Empresa Social, que viene a aglutinar a todas aquellas empresas con una marcada misión social. Es decir, a todas las empresas que reinvierten la mayor parte de sus beneficios en alguna obra social. $Y$ es precisamente en este marco de referencia donde encontramos a las cooperativas, mutuas y asociaciones voluntarias con o sin ánimo de lucro.

En esa pretendida activación social, desde los años 80 han ido cobrando especial importancia las cooperativas de trabajo-asociado y las cooperativas sociales. Estas iniciativas suelen establecerse a nivel local, creando pequeñas firmas que a su vez crean redes entre ellas. Entre las cooperativas sociales, habría que destacar las Cooperativas de Cuidados Sociales (Social Care Co-ops) y las 
Cooperativas de Empleo (Social Employment Co-ops). Todas estas nuevas cooperativas, junto con las empresas sociales (empresas con un objeto similar, pero sin forma jurídica cooperativa), han conseguido incidir significativamente en el empleo de personas con discapacidades.

Estas Cooperativas están obligadas a comerciar en el mercado para poder mantener su capacidad de auto-financiación. Sin embargo, cabría señalar que dichos mercados son en el fondo cuasimercados, ya que es el Estado quien, a través de la concesión de contratos, delega en estas nuevas organizaciones la provisión de estos bienes que hasta ahora eran de competencia pública. Así, se ha observado que la mayoría de las nuevas empresas sociales que se han ido extendiendo concuerdan con una clara tipología de empresas de tamaño limitado, con gran entronque territorial, buenas conocedoras de las necesidades específicas locales, y con una marcada vocación a prestar los servicios que desde los poderes públicos se descentralizan sobre las autoridades locales y demás agentes de los programas de desarrollo local, y muy especialmente en el ámbito socio-sanitario y en el del empleo.

Hemos apreciado cómo en el Reino Unido se hace especial hincapié en una actuación pública hacia la promoción y profesionalización de la sociedad civil, a través de su estructuración en el Tercer Sector.

Como ya hemos adelantado, esta relación entre los poderes públicos y las Empresas Sociales se establecen principalmente en base a contratos, habiéndose constatado que los mismos son cada vez más generalizados para la provisión de ciertos servicios (principalmente servicios sociales). Esta relación contractual establece otra relación entre el financiado y el financiador, ya que la continuidad de la concesión no depende tanto de la capacidad de presión de la empresa externa o de la voluntad de la Administración Pública, como del éxito obtenido por dicha empresa externa en términos de rentabilidad. De este modo, el Gobierno evita que los fondos destinados a ese fin caigan en saco roto y obliga al mismo tiempo a las empresas externas a que desarrollen estructuras que sean competitivas en el mercado.

Por otro lado, y como ya hemos visto, a estos concursos de adjudicación de servicios, las Empresas Sociales acceden como cualquier otra empresa. En la elección del mejor candidato es donde puede actuar el Gobierno, priorizando ciertas "cláusulas sociales" o "cláusulas de inserción" frente a la selección tan sólo en base al precio.

Por último, y atendiendo más en concreto al ámbito sanitario, a raíz de las recientes reformas en su sistema público y en el de cuidados, hemos podido observar cómo se pretende des-institucionalizar el mismo, y desplazar la provisión de dichos servicios a entidades locales y organizaciones de atención a domicilio. Esta política va acompañada de un trasvase de fondos desde el Departamento de Seguridad Social hacia los Departamentos Locales de Servicios Sociales, y es allí en donde se adjudica generalmente a las Cooperativas de Cuidados Sociales. 
De esta manera, el gobierno británico ha impulsado la creación de nuevas Empresas Sociales a través de la concesión de ayudas a usuarios con problemas de salud y, las personas que declaran tener alguna invalidez, problemas de movilidad o necesidad de ser atendidas en casa, han podido acceder a cada vez mayores ayudas sociales. Para la provisión de dichas necesidades, convertidas en nuevas demandas gracias a la financiación pública, se ha ido creando una inmensa red de cooperativas sociales y organizaciones voluntarias (cada vez más profesionalizadas), ya que al tener menor tamaño y tener un conocimiento más cercano, solventan con mayor eficacia los problemas burocráticos de la sanidad pública y son capaces de prestar una atención más personalizada.

\subsection{La Empresa Social: del modelo italiano a la realidad actual}

Nuestra legislación, y más en concreto la Ley 5/2011, de Economía Social, no ha registrado el concepto de "Empresa Social", ni tampoco resulta fácil determinar qué es, como ya señala la profesora Gemma Fajardo ${ }^{25}$, a la vista de la literatura científica. Sin embargo, lo hemos querido traer a colación por la vigencia que empieza a tener determinada doctrina que identifica de alguna forma este tipo de formulación societaria con la empresa de inserción, economía solidaria, nueva economía social o entidad no lucrativa de acción social.

Lo que no cabe duda es que la aprobación en Italia de un nuevo marco normativo para la "Impresa Sociale" o Empresa Social contribuyó sin duda a potenciar el uso de esa denominación y a concretar su sentido. Así, en Italia, la Ley 155/2006, se define la Empresa Social como aquella organización privada, sin fin de lucro, que desarrolla de forma estable o principal una actividad económica de producción o de intermediación de bienes o de servicios de utilidad social, dirigida a realizar fines de interés general.

Por otro parte, el Decreto Ley n 155 de 2006 excluyó del concepto de Empresa Social a las organizaciones que limitan su actividad a la prestación de servicios para sus socios, asociados o partícipes, diferenciando aquella caracterizada por la prestación de servicios de utilidad pública y aquella que tiene como fin la inserción laboral de determinadas personas desfavorecidas o discapacitadas. Según el Decreto Ley, la Empresa Social debe carecer de ánimo de lucro por lo que sus beneficios deberán destinarse al desarrollo de la actividad societaria.

En un esfuerzo de sistematización doctrinal, y siguiendo de nuevo a la profesora Gemma Fajardo26, diremos que la Empresa Social en los nuevos términos en los que se está observando su desarrollo en Europa es un agente cuyo principal objetivo es tener una incidencia social, más que generar beneficios para sus propietarios o socios. Funciona en el mercado proporcionando bienes y/o servicios de

25.- FAJARDO GARCÍA, Gemma, El concepto legal de economía social y la empresa social, Revista Vasca de Economía Social, $n^{\circ} 8$, Bilbao, 2012.

26. - Ibidem. 
manera empresarial e innovadora y utilizando sus excedentes principalmente para fines sociales. Está sometida a una gestión responsable y transparente, en concreto mediante la asociación de sus empleados, sus clientes y las partes interesadas de que se trate en su actividad.

Siguiendo el modelo italiano, encontramos en la actualidad en nuestro mercado dos tipos Empresas Sociales:

a) Aquellas que prestan servicios sociales o suministran bienes y servicios destinados a un público vulnerable (acceso a la vivienda, acceso a los cuidados, ayuda a las personas de edad o con discapacidad, inclusión de grupos vulnerables, guardería infantil, acceso al empleo y a la formación, gestión de la dependencia, etc.).

b) Empresas cuyo modelo de producción de los bienes o servicios persigue un objetivo de fin social (integración social y/o profesional mediante el acceso al trabajo de personas desfavorecidas, sobre todo por razón de su escasa cualificación o de problemas sociales o profesionales que provocan exclusión y marginación), pero cuya actividad puede incluir bienes y servicios que no sean sociales.

La definición de Empresa Social, por tanto, es una cuestión multidimensional en la que se conjugan elementos tradicionales de empresa y de la Economía Social, y que afectan especialmente al objeto social, la motivación económica y los modelos de gestión de este tipo de organizaciones.

Este modelo continental de Empresa Social, con origen en la legislación italiana, en definitiva, lo vemos muy basado en los principios y valores de la Economía Social (no únicamente), frente a la tradición anglosajona, en donde la Empresa Social viene definida por su finalidad; es decir, es una organización donde predominan los fines sociales sobre el capital, sin exigir en muchas ocasiones ninguna cuestión añadida ni mucho menos tipos jurídicos específicos. En el mundo anglosajón, como veíamos, no se exige explícitamente una forma jurídica para estas empresas, pero sin embargo se establece una relación directa entre los objetivos sociales y los sectores económicos en los que se desarrolla la actividad, y que en concreto se centran en educación, sanidad, servicios sociales y energías renovables.

En el Estado español este tipo de empresas, siguiendo en buena forma la trayectoria continental, se concentran en el modelo vinculado a la Economía Social, y más en concreto, si bien no únicamente, bajo tres formas organizativas: las empresas de inserción, los centros de empleo y las cooperativas de iniciativa social 27 .

27.- Sobre las empresas sociales vid., DIAZ-FONCEA, Millán y MARCUELLO, Carmen, Las empresas sociales en España: concepto y características, Revista Vasca de Economía Social, $n^{\circ}$ 8, Bilbao, 2012. Así mismo, vid., AA.VV., Economía Social y Servicios Sociales, CIRIEC, Valencia, 2001; y AA.VV. número $n^{\circ} 75$ (monográfico) de la Revista Economía Pública, Social y Cooperativa de CIRIEC-España, Empresas Sociales y Economía Social, CIRIEC, Valencia, 2012. 
Lo que parece claro es que los regímenes específicos de la Economía Social, más en concreto el cooperativo, están especialmente adaptados a la definición de Empresa Social ya que su gobernanza favorece la participación y la flexibilidad empresarial. Pero, es más, en la Comunidad Autónoma del País Vasco, la dicción del artículo 124, regulador de las cooperativas de integración social, así como los Decretos 64/1999 y 61/2000, reguladores de las cooperativas de utilidad pública y de iniciativa social, respectivamente, abordan perfectamente y desde la seguridad jurídica el marco conceptual que se pretende con la Empresa Social. Por el contrario, referenciar conceptos jurídicos fuera del marco normativo, en este caso de la Economía Social, y en particular del cooperativo, no puede generar más que problemas en la aplicación práctica de la privatización de los servicios públicos sociosanitarios. Todo ello sin perjuicio de la evolución y la concreción normativa que pueda tener en el futuro la denominada por la doctrina "Empresa Social".

\section{7.- La atención a las personas en situación de dependencia}

La entrada en vigor en el Estado español de la Ley 39/2006, de 14 de diciembre, de Promoción de la Autonomía Personal y Atención a las Personas en Situación de Dependencia, supuso el intento de paliar, por lo menos en parte, la situación generada por el envejecimiento demográfico, unido a los cambios experimentados en la composición y hábitos de los núcleos familiares (una de cuyas consecuencias es su menor capacidad de atender y cuidar a sus miembros).

Esta Ley definió un conjunto de prestaciones y servicios que se garantizaban por el sector público en las mismas condiciones para todos los ciudadanos, bajo los criterios de la universalidad de su prestación, carácter público de la misma, igualdad de acceso al derecho y cofinanciación

En el ámbito que nos ocupa, la propia Ley en su preámbulo señalaba que "Es un hecho indudable que las entidades del tercer sector de acción social vienen participando desde hace años en la atención a las personas en situación de dependencia y apoyando el esfuerzo de las familias y de las corporaciones locales en este ámbito. Estas entidades constituyen una importante malla social que previene los riesgos de exclusión de las personas afectadas".

Como hemos señalado, con la nueva Ley de 2006 se reconoció un nuevo derecho con carácter universal y subjetivo, al tiempo que se garantizaba la atención y cuidados a las personas en situación de dependencia, es decir, que no pueden valerse por sí mismas (aquellas que necesitan ayuda para realizar las acciones básicas de la vida), por parte de los poderes públicos. Desde entonces se cuenta en este campo de actuación con una red de utilización pública, diversificada y que integra de forma más o menos coordinada, centros y servicios, públicos y privados, debidamente acreditados. 
Obviando los aspectos técnicos de la norma, diremos que atendiendo dependiendo al grado de dependencia se garantizan -con diferente grado de reconocimiento social- los servicios siguientes: Servicio de Prevención (en situaciones de dependencia); Teleasistencia; Ayuda a Domicilio (incluyendo atención a las necesidades del hogar y cuidados personales); Centros de Día y de Noche; Servicios de Atención Residencial; Centros de Atención a Dependientes (con discapacidad psíquica y/o física). Todo ello sin perjuicio de las prestaciones económicas a las que hubiera lugar y de conformidad con la norma.

Por otro lado, la Comunidad Autónoma del País Vasco posee competencia exclusiva en materia de Servicios Sociales, lo que se ha concretado en la Ley 12/2008, de 5 de diciembre de Servicios Sociales, a través de la cual se ha ido desarrollando un Sistema Público de Servicios Sociales en su ámbito competencial, constituido por un conjunto integrado de recursos, actividades, prestaciones y equipamientos, de titularidad pública o privada concertada, y en colaboración y coordinación en cualquier caso con las Diputaciones Forales.

La Comunidad Autónoma del País Vasco también ha seguido el afianzamiento de la responsabilidad pública y el aprovechamiento integral de los recursos existentes; así como la cooperación de los diversos agentes a través de la coordinación del conjunto de las actuaciones públicas y privadas.

El sistema por el que se aboga en la actualidad es el referido a servicios que se esfuercen en el mantenimiento de las personas en su entorno habitual, en la proximidad de los servicios y su descentralización (equilibrio y homogeneidad territorial), en la atención integral y continua, y en la personalización y la calidad de la atención. Y es en este marco y respecto a la intervención de la iniciativa privada en la prestación de servicios de responsabilidad pública, a través de los ya estudiados sistemas de gestión indirecta y concertada, cuando se deben establecer autorizaciones y homologaciones administrativas que, con independencia del tipo societario, garanticen la calidad en la asistencia si la misma ha quedado delegada en el ámbito privado.

En este marco de prestaciones, nos encontramos con los siguientes servicios:

a) Servicio de Ayuda a Domicilio: Es de naturaleza asistencial y preventiva, y está destinado a mejorar la calidad de vida de aquellas personas que, por su edad, discapacidad o falta de autonomía, no pueden desenvolverse de manera independiente en las actividades básicas de la vida diaria y precisan por ello de la ayuda de una tercera persona. Este recurso les permite permanecer en su residencia habitual. Principalmente se ofrecen servicios de apoyo doméstico y de atención y apoyo personal, y en algunos casos se incluyen otras prestaciones para la realización de las actividades de la vida diaria.

b) La Teleasistencia, también denominada telealarma: Está dirigido a personas mayores de 60 años o personas con discapacidad de cualquier edad que viven solas o permanecen solas la mayor parte del día y se encuentran en situación socio-sanitaria de riesgo. El objetivo es mejorar la calidad 


\section{POSIBILIDADES DEL COOPERATIVISMO EN UN NUEVO MODELO DE SERVICIOS PÚBLICOS SOCIOSANITARIOS Y SU CONCRECIÓN EN EL PAÍS VASCO}

de vida de estas personas fortaleciendo su sentimiento de autonomía y seguridad. Este servicio se concreta en la instalación en el domicilio de un equipo técnico especial capaz de desencadenar una llamada de alarma ante una situación de emergencia.

c) Los Centros de Día: Son recursos sociales concebidos como una alternativa intermedia entre la Ayuda a Domicilio y la estancia en Residencia. Son un recurso abierto que promueve la convivencia en una determinada población o barrio en donde se ofrecen servicios de asistencia social y otros de carácter educativo y recreativo. Los centros de día son considerados como un centro gerontológico terapéutico y de apoyo a la familia que, de forma ambulatoria, presta atención integral y especializada a la persona mayor en situación de dependencia.

d) Finalmente, cabe recoger los Centros Residenciales: Figura en la que se incluyen por un lado los centros de corta estancia como albergues, centros de acogida, pisos y centros de respiro, y, por otro, las residencias de larga estancia, en las que se incluyen además de las residencias los pisos tutelados, viviendas comunitarias u hogares funcionales, los apartamentos tutelados o las unidades de convivencia asistida.

La orientación del sistema a la colaboración y coordinación público-privado, y el apoyo a las entidades sin ánimo de lucro, nos remiten una vez más a la Cooperativa social y/o de utilidad pública como uno de los instrumentos más adecuados a la hora de gestionar este tipo de servicios, sobre todo al elevarse incluso a rango de Ley la justificación de la ausencia del ánimo de lucro en determinados procesos de concertación y concurso para la adjudicación de estos servicios ${ }^{28}$.

28.- Son muchas las referencias de sociedades cooperativas que en la actualidad trabajan en el ámbito sociosanitario en colaboración con la Administración Pública. Así, cabe destacar, a título tan sólo de ejemplo, y por todas:

Gestión de Servicios Residenciales, S. Coop. (Arrasate-Mondragón) es una cooperativa de la Corporación Mondragón comprometida con el entorno a través del empleo local que presta servicios a Personas Mayores a través de Residencias, Servicios de Ayuda a Domicilio, Centros de Día, Viviendas Comunitarias y Viviendas Tuteladas. Ref.: www.gsr.coop

Servicios Sociales Integrados, S. Coop. (Bilbao), empresa dedicada a la prestación de servicios en el apoyo social a personas con déficit de autonomía y/o en situación de dependencia, atención socio-sanitaria, apoyo socioeducativo y psicosocial para cuidadores, inserción sociolaboral, acceso a prestaciones elementales, urgencias sociales y formación para la cualificación profesional y capacitación. Ref.: www.grupossi.es

Arabako Laguntza, S. Coop. (Vitoria-Gasteiz) atiende a las personas dependientes y mayores no dependientes a través del Servicio de Ayuda a Domicilio, desarrollan un servicio socio-sanitario que tiene como objeto fundamental el de, a través de una atención directa en el hogar, favorecer la permanencia en el mismo de las personas con dificultades para el desarrollo de las actividades básicas de la vida diaria, mejorando su calidad de vida y autonomía personal. Ref.: www.arabakolaguntza.com

Oizpe Egoitza, S. Coop. (Munitibar-Bizkaia) es un centro gerontológico de iniciativa social cuyo objetivo primordial es proporcionar calidad de vida a las personas con algún grado de dependencia que viven en el centro temporal o permanentemente, así como a sus allegados. Ref.: www.oizpe.com

Ambulancias Gipuzkoa, S. Coop. (Urnieta), es una empresa líder en su sector con importantes acuerdos con el Departamento de Sanidad del Gobierno Vasco para atender al Area Sanitaria en ámbitos territoriales, aportando ambulancias asistenciales de soporte vital avanzado. Además, presta sus servicios para Mutuas de Trabajo -además de para Osakidetza- cubriendo así también, tanto accidentes de trabajo, como traslados nacionales e internacionales con acompañamiento con médico y personal sanitario, servicios preventivos, etc. Ref.: www.ambulanciasgipuzkoa.com

Agintzari, S.Coop. (Bilbao), opera en el ámbito de la intervención social trabajando en la puesta en marcha de propuestas innovadoras y en la gestión de servicios de calidad orientados a la superación de las necesidades sociales de personas y colectivos en situación de dificultad. La gestión de estos servicios se organiza en tres líneas de actividad: intervención comunitaria, acogimiento y adopción e intervención en violencia y conflictos relacionales. Ref.: www.agintzari.com.

CIRIEC-España, Revista de Economía Pública, Social y Cooperativa 
Así, si bien el liderazgo público en el desarrollo de los Servicios Sociales es incontestable, tanto en lo referente a los tiempos recientes como al futuro inmediato, desde el reconocimiento de una intervención en cooperación y coordinación con la iniciativa privada, creemos debe ir conformándose un espacio para las Entidades de la Economía Social, y específicamente para las Cooperativas, caracterizado por la solvencia, prestigio, buen hacer y conocimiento; al tiempo que precisamente sea ese sector el capaz de tener iniciativas, hacer propuestas y dar nuevos impulsos en este campo.

El movimiento cooperativo vasco tiene unas señas de identidad reconocidas vinculadas con la calidad, las buenas prácticas, la profesionalidad, el prestigio, su compromiso con el desarrollo de la sociedad vasca, etc. y que se extienden como garantía al conjunto de sus actividades y servicios que a lo largo de su historia ha ido desarrollando. Al menos así es generalmente reconocido, por lo que debe constituirse en un agente socioeconómico de relevancia en el País Vasco, ocupando también un papel destacado no sólo en el desarrollo de la atención a la dependencia, sino de los servicios sociosanitarios en general.

\section{8.- Conclusiones}

Primera.- El Servicio público es una actividad que realizan los poderes públicos para satisfacer las preferencias, expectativas, demandas y necesidades de los ciudadanos. Esta actividad material 0 técnica en la prestación de servicios finales al público en general, y basada en principios de igualdad, debe ser de titularidad pública, si bien no supone necesariamente que deba ser prestada directamente por una Administración Pública.

Segunda.- Actualmente nos encontramos con una tendencia de reforma del sector público en la búsqueda de una mejora de la capacidad de gestión económica y en la prestación de sus servicios desde la eficacia. En este marco, la New Public Management (Nueva Gestión Pública) señala que la Administración Pública debiera emular las mejores prácticas de las instituciones del sector privado y que si bien no se puede manejar la Administración Pública como una empresa, sí se puede dirigir con espíritu emprendedor.

Tercera.- En este marco emerge la prestación de los servicios públicos por operadores privados y, más en concreto, por Entidades de Economía Social, debido a que se ha constatado que la participación del ciudadano-cliente en la gestión de los servicios ha dado buenos resultados en el caso por ejemplo de experiencias habidas en el campo sociosanitario y de los servicios sociales. 
Cuarta.- Son varios los instrumentos que los poderes públicos utilizan para la prestación de sus servicios. Entre ellos nos encontramos con la gestión de los servicios por parte de empresas, por ejemplo, de la Economía Social, pudiéndose en el caso de estos contratos establecerse cláusulas sociales que favorezcan la adjudicación a estas Entidades en los concursos públicos, al estar la contratación administrativa sujeta al interés público.

Quinta.- La Economía Social pone en evidencia un modelo de empresa que no se caracteriza por el tamaño o el sector de actividad, sino por el respeto de valores comunes como la primacía de la democracia, de la participación de los actores sociales y de la persona, y del objeto social sobre el beneficio individual; la defensa y la aplicación de los principios de solidaridad y de responsabilidad; la conjunción de los intereses de los miembros usuarios con el interés general; el control democrático ejercido por los miembros; la adhesión voluntaria y abierta; la autonomía de gestión y la independencia respecto de los poderes públicos; y la asignación de lo esencial de los excedentes al servicio de la consecución de objetivos como el desarrollo sostenible, el interés de los servicios a los miembros y el interés general (Resolución del Parlamento Europeo de 19 de febrero de 2009, sobre Economía Social).

Sexta.- En España, la Ley 5/2011, de 29 de marzo, de Economía Social ha definido que conforman la Economía social las cooperativas, mutualidades, fundaciones, asociaciones que lleven a cabo actividad económica, sociedades laborales, empresas de inserción, centros especiales de empleo, cofradías de pescadores y sociedades agrarias de transformación.

Séptima.- La Cooperativa es una forma de organización empresarial basada en la estructura y funcionamiento democráticos. Su actividad se desarrolla atendiendo a los principios cooperativos: la adhesión voluntaria y abierta de los socios (puerta siempre abierta), la gestión democrática (una persona=un voto), la participación económica de los socios (participación en los beneficios en función del trabajo del socio y no de su capital), la educación, formación e información (escuela de democracia económica) y el interés por la comunidad (desarrollo sostenible y compromiso democrático con lo local). El modelo cooperativo se caracteriza por recoger en su seno una serie de valores y normas de comportamiento ético que deben guiar a los cooperativistas en la toma de decisiones, tanto en las tareas de gobierno interno (órganos sociales, órganos directivos y de gestión, socios/as), como externo (relaciones con grupos de interés, trabajadores, clientes, proveedores, instituciones y sociedad en general).

Octava.- El modelo cooperativo, que debe ser específicamente fomentado por mandato constitucional, presenta en Euskadi garantías para el sector público, como la existencia de un Registro administrativo propio o un servicio de resolución de conflictos, también en sede pública, que hacen de esta fórmula especialmente atractiva en la actualidad para la realización de cualquier actividad o prestación de servicios (incluidos los públicos). 
Novena.- De conformidad con el Decreto 64/1999, de 2 de febrero, del Gobierno Vasco, las sociedades cooperativas pueden ser calificadas de utilidad pública, cuando contribuyan a la promoción del interés general de Euskadi. A estos efectos, se entiende que sirven al interés general de Euskadi aquéllas en cuyo objeto social sean primordiales los siguientes fines: asistencia social, cívicos, educativos, culturales, científicos y de investigación, deportivos, sanitarios, de cooperación para el desarrollo, defensa del medio ambiente, fomento de la economía social, fomento de la paz social y ciudadana, o cualesquiera otros fines de naturaleza análoga. Podrán ser declaradas de utilidad pública aquellas que, en el marco de la actividad ya definida, además carezcan de ánimo de lucro.

Décima.- Pueden asimismo ser declaradas las sociedades cooperativas como de iniciativa social (Decreto 61/2000, de 4 de abril, por el que se regulan las Cooperativas de Iniciativa Social) cuando desarrollan su actividad en el ámbito de la prestación de servicios sociosanitarios, educativos, culturales o medioambientales; e incluso conformarse como de integración social (Ley 4/1993, de 24 de junio de Cooperativas de Euskadi).

Undécima.- Existen experiencias internacionales, tanto en la tradición anglosajona (Reino Unido) como latina (Italia) que ejemplarizan cómo se ha concretado la activación social en el ámbito sociosanitario a través de las cooperativas y empresas sociales.

Duodécima.- En relación a la Promoción de la Autonomía Personal y Atención a las Personas en Situación de Dependencia, y a los Servicios Sociales en general, se ha ido afianzando tanto la responsabilidad pública, el aprovechamiento integral de los recursos existentes, como la cooperación de los diversos agentes a través de la coordinación del conjunto de las actuaciones públicas y privadas. Esta colaboración público-privada nos hace ver a la Cooperativa, y más en concreto la de iniciativa social y/o de utilidad pública, como uno de los instrumentos más adecuados a la hora de gestionar este tipo de servicios.

Decimotercera.- Por último, el movimiento cooperativo vasco tiene unas señas de identidad reconocidas vinculadas con la calidad, las buenas prácticas, la profesionalidad, el prestigio, y su compromiso con el desarrollo de la sociedad vasca, que se extienden como garantía al conjunto de sus actividades y servicios, y que a lo largo de su historia ha ido desarrollando. Al menos así es generalmente reconocido por lo que debe constituirse en un agente socioeconómico de relevancia en el País Vasco que debería ocupar también un papel destacado no sólo en el desarrollo de la atención a la dependencia, sino de los servicios sociosanitarios en general. 


\section{Bibliografía}

AA.VV. (2012): Empresas Sociales y Economía Social, CIRIEC-España, Revista Economía Pública, Social y Cooperativa, número 75 (monográfico), Valencia.

ÁBALOS MECO, J.L. \& ILLÁN SAILER, J.C. (2006): La gestión y prestación de los servicios públicos en el marco de la descentralización, Instituto Universitario de Desarrollo y Cooperación, Madrid.

BARRETT, F. (1998): Creativity and Improvisation in Jazz and Organizations: Implications for Organizational Learning, Organization Science.

CIRIEC-ESPAÑA. Disponible en [http://www.ciriec.es].

CONF. COOPERATIVE FEDERAZIONES SANITÀ, Mission Document, 2012.

CONSEJERÍA DE SALUD Y BIENESTAR SOCIAL DE CASTILLA LA MANCHA (2009): Relaciones contractuales de los profesionales médicos en los sistemas públicos de salud en países europeos seleccionados.

CO-OPERATIVE COLLEGE FOR THE DEPARTMENT OF INTERNATIONAL DEVELOPMENT (2004): Promoting co-operatives: a guide to ILO Recommendation 193, Manchester.

DEPARTAMENTO DE SANIDAD Y CONSUMO DEL GOBIERNO VASCO (2010): Estrategia para afrontar el reto de la cronicidad en Euskadi, Gobierno Vasco.

DIAZ-FONCEA, M. \& MARCUELLO, C. (2012): "Las empresas sociales en España: concepto y características", Revista Vasca de Economía Social, 8.

DUSHEIKO, M., GRAVELLE, H., YU, N. \& CAMPBELL, S. (2007): The impact of budgets for gatekeeping physicians on patient satisfaction: evidence from fundholding, J Health Econ.

FAJARDO GARCÍA, G. (2012): "El concepto legal de economía social y la empresa social", Revista Vasca de Economía Social, 8.

FIORENTINI, G., IEZZI, E., LIPPI BRUNI, M. \& UGOLINI, C. (2010): Incentives in primary care and their impact on potentially avoidable hospital admissions, Eur J Health Econ.

FLETCHER, J. (2000): "Do out-of-hours co-operatives improve general practitioners' health", British Journal of General Practice.

FLOGIA, E. (2012): Integrated or not integrated Which future for Primary Care Groups (PCGs), European Health Management Association. 
FRIEDMANN, R. (2003): La Gestión Pública en el siglo XXI. Anticipando los cambios que vienen. Hacia un Sector Público Inteligente y en constante Aprendizaje, Instituto de Estudios y Gestión Pública, Madrid.

FUNDACIÓN ESPRIU. Disponible en [http://www.fundacionespriu.coop].

GALERA, G. (2004): The evolution of the co-operative form: an international perspective, Trento.

GIDDENS, A. (1997): Konsequenzen der Moderne, Frankfurt.

GOODWIN, N., DIXON J., FEELEY, D. \& HAM, C. (2008): Country case study: UK Primary care in England and Scotland, The Rockefeller Foundation Bellagio Study and Conference Center.

GOSDEN, T. \& TORGERSON, D.J. (1997): The effect of fundholding on prescribing and referral costs: a review of the evidence, Health Policy.

HALLAM, M. \& HENTHORNE, K. (1999): Cooperatives and their primary care emergency centres: organisation and impact, Health Asessment Technology.

HATCH, M.J. (1997): Jazzing, Up The Theory of Organizational Improvisation, Advances in Strategic Management.

HÖCKERTIN, C. (2008): Control and participation for employees within geriatric care: does ownership make a difference?, http://sescam.jccm.es/web1/profesionales/home/CTU_OPA_REPULLO_FREIRE.pdf.

JURADO MORENO, J. (2009): Autogestión en la atención primaria española, SEMG, Sociedad Española de Médicos Generales y de Familia.

KAY, A. (2002): "The abolition of the GP fundholding scheme: a lesson in evidence-based policy making", British Journal of General Practice.

LAAMANEN, R., OVRETVEIT, J., SUNDELL, J., SIMONSEN-REHN, N., SUOMINEN, S. \& BROMMELS, M. (2006): "Client perceptions of the performance of public and independent not-for-profit primary healthcare", Scand J Public Health.

LEDESMA, A. (2012): ¿Autogestión o autonomía de gestión?, Informe SESPAS.

LEDESMA, A. (2005): "Entidades de base asociativa: un modelo de provisión asistencial participado por los profesionales sanitarios. Valoración actual y retos futuros", Rev. Adm. Sanit.

LEGESMA ZABALEGUI, S. (2006): Cláusulas sociales, contratación pública e inserción social, Bilbao.

LEIBOWITZ, R., DAY, S. \& DUNT, D. (2003): A systematic review of the effect of different models of after-hours primary medical care services on clinical outcome, medical workload, and patient and GP satisfaction, Family Practice.

MARTíN MARTíN, J.J. (2003): Nuevas formulas de gestión en el ámbito sanitario. 
MERINO HERNÁNDEZ, S. (Director) (2008): Manual de Derecho de Sociedades Cooperativas, VitoriaGasteiz.

MILANESE, G. (2012): 2012 UN International Year of Co-operatives, Cyprus Conference: EU innovation policy \& new co-operative development.

MUR-VEEMAN, I., HARDY, B., STEENBERGEN, M. \& WISTOW, G. (2003): Development of integrated care in England and the Netherlands: managing across public-private boundaries, Health Policy.

O'SULLIVAN, B., KEANE, A.M. \& MURPHY, A.W. (2005): "Job stressors and coping strategies as predictors of mental health and job satisfaction among Irish general practitioners", Irish Medical Journal.

OSBORNE, D. \& GAEBLER, T. (1994): La reinvención del gobierno, Barcelona.

PAZ CANALEJO, N. (1980): "La Constitución y las Cooperativas", Documentación Administrativa, 186.

PEINADO GRACIA, J.I. (Director) (2013): Tratado de Derecho de Cooperativas, Valencia.

PEZZINI, E. (2012): La capacité d'innovation et d'exploration des nouveaux secteurs coopératifs: Le cas italien.

PRADOS DE REYES, F.J. \& VIDA SORIA, J. (1985): "Comentarios al artículo 129. La participación social en el texto de la Constitución". En: Comentarios a las Leyes Políticas y Constitución de 1.978, Madrid.

PULIDO QUEVEDO, M. (1986): La Constitución española, Pamplona.

RABELAIS, C.M. (2001): Unimed: historia e caracteríticas da cooperativa de trabalho médico no Brasil, Cad Saúde Pública, Rio de Janeiro.

RAJASEKHARAN, K. \& RAZUM, O. (2003): "Health co-operatives: review of international experiences", Croatian Medical Journal.

REPULLO LABRADOR, J.R. \& FREIRE CAMPO, J.M. (2009): Relaciones contractuales de los profesionales médicos en los sistemas públicos de salud en países europeos seleccionados. Médicos en cinco Sistemas Sanitarios Integrados Europeos, Consejería de Sanidad de la Junta de Comunidades de Castilla-La Mancha, Toledo.

ROBSON, K. (2011): The National Health Service in Scotland: Subject profile, Spice, the Information Centre.

ROMANO, D.P. (2012): Il supporto delle Coop MMG e loro Consorzi ai Medicini di Famiglia associati in Emilia Romagna.

SÁNCHEZ-CARO, J. (2000): "Régimen jurídico de las nuevas formas de gestión en la sanidad española (la perspectiva del Instituto Nacional de la Salud)", Revista de Administración Sanitaria. 
SCOTTISH GOVEMMENT (2012): Integration of adult health and social care in Scotland, Consultation on proposals.

SHIELDS, M.C., PATEL, P.H., MANNING, M. \& SACKS, L. (2010): A model for integrating independent physicians into accountable care organizations, Health Aff (Millwood).

SHORTELL, S.M. \& PECK, W.A. (2006): "Enhancing the potential of quality improvement organizations to improve quality of care", Ann Intern Med.

SIMOENS, S. \& SCOTT, A. (2003): "How are Scottish integrated primary care organisations managed?", Journal of Health Organization and Management.

SIMOENS, S. \& SCOTT, A. (2005): Voluntary or compulsory health care reform? The case of primary care organisations in Scotland, Health Policy.

STARFIELD, B. (2012): Primary care: an increasingly important contributor to effectiveness, equity, and efficiency of health services, SESPAS report.

TEDESCHI, P. (2007): Developments in the Primary Care sector, Centre for Research on Health and Social Care Management.

UGARTE, L. (2004): Sinfonía o Jazz, Koldo Saratxaga y el modelo Irizar, Barcelona.

UNITED NATIONS (1997): Cooperative Enterprise in the Health and Social Care Sectors: A Global Survey.

WATT, G., IBE, O. \& MCLELLAND, N. (2009): Study of Community Health Partnerships.

WEEKS, W.B., GOTTLIEB, D.J., NYWEIDE, D.E., SUTHERLAND, J.M., BYNUM, J. \& CASALINO, L.P. (2010): Higher health care quality and bigger savings found at large multispecialty medical groups, Health Aff (Millwood).

WILKIN, D. (2002): "Primary care budget holding in the United Kingdom National Health Service: learning from a decade of health service reform", Med. J.

WILSON, R.P., HATCHER, J., BARTON, S. \& WALLEY, T. (1999): "Therapeutic substitution and therapeutic conservatism as cost-containment strategies in primary care: a study of fundholders and non-fundholders", Br. J. Gen Pract.

WOODS, K. \& MC COLLAN, A. (2012): "Progress in the development of integrated mental health care in Scotland", International Journal of Integrated Care.

WOODS, K. (2001): "The development of integrated health care models in Scotland", Integrated Journal of Integrated Care.

ZOTTI, A.M., OMARINI, G. \& RAGAZZONI, P. (2008): "Can the type of organisational structure affect individual well-being in health and social welfare occupations?", Giornale italiano di medicina del lavoro et ergonomia. 